\title{
The Challenges of Community Engagement
}

\author{
Craig Cormick
}

Received: 1 December 2009 /Accepted: 6 September 2010/Published online: 3 October 2010

(C) The Author(s) 2010. This article is published with open access at Springerlink.com

\begin{abstract}
Lyons and Whelan provide a useful list of recommendations as to how community engagement on nanotechnology could be improved, which very few people working in community engagement could disagree with. However, as the conclusions of any study are dependent on the data obtained, if more data had been obtained and analysed then different conclusions might have been reached. Addressing the key issues in the paper and providing more data, also allows an opportunity to expand on current issues relating to community engagement on nanotechnology and the challenges it provides for practitioners.
\end{abstract}

Keywords Community engagement $\cdot$ Public attitudes $\cdot$ National enabling technologies strategy

Lyons and Whelan [4] provide a useful list of recommendations as to how community engagement on nanotechnology could be improved, with which very few people working in community engagement could disagree. However, as the conclusions of any study are dependent on the data, if more data had been obtained and analysed then different conclusions might have been reached. Addressing the key issues in the paper and providing more data, also allows an

C. Cormick $(\bowtie)$

Public Awareness and Community Engagement, Department of Innovation, Industry, Science and Research, National Enabling Technologies Strategy, Canberra, Australia

e-mail: craig.cormick@innovation.gov.au opportunity to expand on current issues relating to community engagement on nanotechnology and the challenges it provides for practitioners.

The paper by Lyons and Whelan is underpinned by three key arguments: that government nanotechnology community engagement activities are designed to favour and advance industry interests; that community stakeholders are only engaged in downstream consultation, and that nano-engagement is disconnected from policy formulation.

Firstly, that government and industry have close and mutual interests is as true as stating that government and the community have close and mutual interests, as the community elects governments. A more relevant question is how this relationship is managed with equity to other key stakeholders, including researchers, interest groups and the public. One significant way of including public interests into policy development is through programs such as the Department of Innovation, Industry, Science and Research's Public Awareness and Community Engagement program - as long as it is defensible against the criticisms raised by Lyons and Whelan.

Addressing the issue of industry bias first, the paper makes claims such as: "similarly optimistic statements are routinely made by Australian Government representatives in deliberative forums, demonstrating the extent to which political support for nanotechnologies is being garnered around a narrow set of economic imperatives".

This is however at odds with the majority of engagement activities undertaken by the Australian Government. For example, from 2007 to 2008 the 
then Australian Office of Nanotechnology's major engagement activities were a nation-wide series of public forums, expressly designed to allow for public debates free of industry input - but this did include groups with predominantly anti-industry agendas, such as Friends of the Earth, as speakers. The forums were recorded and readers can view the lists of speakers and vodcasts of their talks can be viewed online at www. innovation.gov.au/nets, to examine any such 'optimistic' statements by government representatives.

Moving on to upstream engagement, one of the objectives of the forums was to expose researchers to representatives of the community and enable them to obtain direct feedback on their research - often earlystage research. Discussions on the need for upstream engagement has been a constant one amongst government agencies and research institutions working on nanotechnology engagement over the past decade, and has led to many forums where scientists and the public can discuss early stage research. In addition to the public forums described above engagement activities have included scientists talking to Rotary clubs and the University of the Third Age, as well as pub discussions and nanodialogues (reports are also available at www.innovation.gov.au/nets).

More work in this area will be done, to enable a more rigorous evaluation, but evidence to date is consistent with the literature on upstream engagement and public acceptance [8]. Feedback from scientists taking part has also shown that they value the opportunity to test their research ideas on members of the public, who may suggest new fields of enquiry or demand that certain concerns be better addressed. This is consistent with research findings that indicate that jointly-developed scenarios relating to new technologies have been shown to be more effective at teasing out issues related to their development than when the end points are assumed [7].

It is unfortunate that the paper concentrates overly on just one major activity, the Social Inclusion and Engagement Workshop, held in 2008, and the analysis of it does not well reflect the independent report that was written (also available on the website). Again there is an accusation of industry-bias, but the numbers of attendees, as stated in the report, were Industry 5, Researchers 9, Consumer representatives 8 , Government 15, and NGOs and Change agents 8 .

And even to consider the Government representatives as a single block doesn't recognise the huge diversity of points of view that exist in different government agencies. The relationships between different government departments, research agencies and regulators is a very complex web of often different interests and priorities, often played out in protracted negotiations and consultations. As nanotechnology cuts across the responsibility of so many government agencies, it requires co-ordination with inputs from a wide variety of interests. Not all government agencies are good at public engagement, nor know quite what to do with the outcomes of engagement activities, but it is well understood that it is something that is vital to undertake - often driven by the lesson that the divide between the public and policy development on GMOs could have been narrowed with better early engagement.

The workshop was seeking to address a real issue in community engagement, that unless all key players understand and are involved in the process you get diminished outcomes. One lesson that has been gained by the Government from working with partners in the OECD, and through exposure to experts like Professor Arie Rip of the Netherlands, is that many engagement activities don't really find many things new, and many have trouble translating their engagement outcomes into actual policy outcomes when not all key stakeholders have buy-in to the process [5].

This brings us to the third criticism of disconnect from policy formulation. Strangely, one of the criticisms made is of public attitude research conducted by the Government, stating that as only $8 \%$ of the population polled know what nanotechnology is and how it works, that represents only 88 individuals with informed opinions that would "appear a perilous foundation for government policy". This is not only at odds with the argument that community engagement activities are disconnected from policy formulation, but represents a misunderstanding of the purpose of public attitude research, which were dealt with in more detail in a previous issue of NanoEthics [3], explaining how it provides a baseline for measuring public attitudes that enable policy to align with public aspirations, but also enables a way of measuring attitude change in society.

Another lesson that has been learned from public engagement activities in Australia is that it is difficult to attract and maintain public interest in a debate being conducted between interest groups, particularly 
when it is defined by polarised extremes of those passionately for and against the technology-neither of which align well with the broad public interests in hearing a balanced account of the relevance of different applications to their lives. This is in many ways a more relevant discussion on public engagement, how to frame engagement activities that are most relevant to different sections of the public, with the majority of the public looking for moderate and balanced information, enabling them to make their own judgements.

To quote from a recent paper in Science and Engineering Ethics [2], "Having undertaken a series of nation-wide community forums on nanotechnology, providing information and hearing from the public, a key challenge indentified in Australia was how to engage with the unengaged rather than the already engaged - who tend to make up the audience for such events."

The National Enabling Technologies Strategy has now begun a series of nanodialogues on different topics such as water, bionics and new materials, recruiting members of the public who are generally disinterested in science and technology, and then engaging them in science and technology conversations. The parameters of the dialogues tend to be that the participants lead the discussions more than would happen in a focus group, that technologies are framed in terms of applications, and the discussions lead to what type of a world we want to live in. This last point is of course the key question for community engagement and the type of dialogue that needs to be heard from all members of society.

The key findings from the nanodialogues so far have been that disengaged and unengaged members of the public have different values, interests and levels of awareness in science and technology issues to those sections of the public who tend to self-select to attend most information or engagement activities. They tend to have had poor experiences with science at school that has turned them off science, they tend to seek information on science and technology issues primarily from friends and family, and they respond to S\&T discussions overwhelmingly in terms of their applications only.

These segments of the public make up about 35\% of the public [6] - a not insignificant amount of people - who, to date, have not been engaged with well in community engagement activities. This is a real challenge for contemporary community engagement across a wide range of technologies-how do you ensure that engagement activities encompass all different publics, defined by the National Enabling Technologies Strategies engagement work as broadly: activist publics, affected publics, interested publics and disinterested publics?

To paraphrase Senator Kim Carr, Minister for Innovation, Industry, Science and Research, community engagement matters because democracy matters [1].

And even if it is not well understood, nor overly apparent without a full examination, engagement activities should be underpinned by principles similar to those outlined by Whelan and Lyons in their recommendations. They are, after all, an articulation of best practice and all agencies involved in community engagement are seeking to find ways to achieve this.

Open Access This article is distributed under the terms of the Creative Commons Attribution Noncommercial License which permits any noncommercial use, distribution, and reproduction in any medium, provided the original author(s) and source are credited.

\section{References}

1. Carr K (2010) Speech to the Australian Science Communicators National Conference, 8 February

2. Cormick C (2009) Piecing together the elephant: public engagement on nanotechnology challenges. Sci Eng Ethics 15(1):81-96

3. Cormick C (2009) Why do we need to know what the public thinks about nanotechnology? Nanoethics 3:167-173

4. Lyons K, Whelan J (2009) Community engagement to facilitate, legitimize and accelerate the advancement of nanotechnologies in Australia, NanoEthics 4

5. OECD Working Party on Nanotechnology workshop on best practice engagement with the general public in nanotechnology, Delft, The Netherlands, 29-30 October 2008

6. Quantum Market Research (2007) Community interest and engagement with science and technology in Victoriaresearch report, Victorian Department of Innovation, Industry, and Regional Development (DIIRD)

7. Robinson DKR (2009) Co-evolutionary Scenarios: an application to prospecting futures for the responsible development of nanotechnology. Technol Forecast Soc Change 76(9):1222-1239

8. Wilsdon J, Willis R (2004) See through science: why public engagement needs to move upstream. Demos, London 